\title{
A method for construction of an energy-efficient ice floating pier in the Arctic using hardened ice
}

\author{
$G L$ Kagan $^{1, *}, L R$ Mukhametova ${ }^{2}$ and $A Y$ Velsovskij $^{1}$ \\ ${ }^{1}$ Department of Highways, Vologda State University, Lenina ul. 15, 160000, Russia \\ ${ }^{2}$ Kazan State Power Engineering University, Kazan, Russia
}

\begin{abstract}
This paper presents studies on increasing the ice strength using various additives. It is indicated that addition of wood fiber (artificial composition) and vegetable fiber (natural composition - frozen peat) to ice is an energy-efficient method to increase its strength. This enhances the possibilities of using ice during building and construction works in the Arctic. As an example, the authors proposed a floating ice pier design.
\end{abstract}

\section{Introduction}

One of the directions of the Russian state program "Socio-economic development of the Arctic zone of the Russian Federation" is to develop coastal infrastructure during reclaiming of the Arctic zone. This work should have a fast, but at the same time rational, resourcesaving approach, so it is important to use proprietary technologies that make it possible to obtain energyefficient constructions at relatively low costs. These constructions have to solve the problems of defense, national security and industrial development, including the placement of energy facilities. One of such technologies is the design and method of construction an energy-efficient ice floating pier in the Arctic using hardened ice.

Therefore, the purpose of this study was to develop a technological platform - a floating ice pier using hardened ice. The purpose of this pier is mooring and safe parking of ships and vessels, as well as other offshore facilities, loading and unloading operations along the entire length of the pier using pneumatic wheels and caterpillar tracks cranes of various carrying capacities, placement of various technological and power equipment. It should meet the following criteria:

- Local materials should be used to the maximum extent possible during its production;

- The cost of production and operation should be lower than that of analogues of floating piers or stationary piers under comparable conditions;

- It should provide an ability of quick erection on site;

- It should provide year-round use.

\section{Materials and methods}

In the Arctic, the main local building material is ice. Ice is an accessible and very widespread substance in nature.
Today this material finds its application in construction. In the northern regions of Russia, ice is used to strengthen the roadbed in the winter ("winter roads"), however it is necessary to solve the problem of reducing the coefficient of adhesion of wheel to road.

Ice is also used in the construction of ice crossings for cars and trains. An interesting historical fact is the construction of the largest railway ice crossing through Lake Baikal in 1904, which connected the eastern and western branches of the Great Siberian Route.

Regular ice has a limited usefulness even at low temperatures, due to its low strength characteristics, in particular tensile strength, and the brittle nature of fracture. For hardening of ice, various additions can be used that act as reinforcing materials, and the result is a building material - ice concrete.

Studies on improving the strength characteristics of ice using various additives were carried out by G.L. Kagan in the laboratory of the Arctic and Antarctic Research Institute [1] as well as by other authors [2-7]. Sawdust, fiberglass, cotton and wood fibers, and other materials were used as additives. The efficiency of the obtained compositions from hardened ice depends both on freezing of ice crystals with reinforcing fibers, as well as on the total number of fibers and their strength. The studies [8] showed that the most effective additive to ice providing increased strength characteristics is wood fiber. It provides an increase in tensile strength, including quadruple bending, and eliminates the brittle nature of fracture. When the ultimate compressive loads are reached, ice deforms as a plastic material without visible fracture. Wood fiber is a technological product used in the pulp and paper industry. However, for the regions of the Arctic and the Far North, it is not the most accessible material.

Peat is one of the most widespread materials in the north of the Russian Federation. Owing to the cold climate and high humidity within a long period, northern

* Corresponding author: $\underline{\mathrm{v} 2 \mathrm{u} @ y a n d e x . r u}$ 
Table 1. Elastic characteristics of ice.

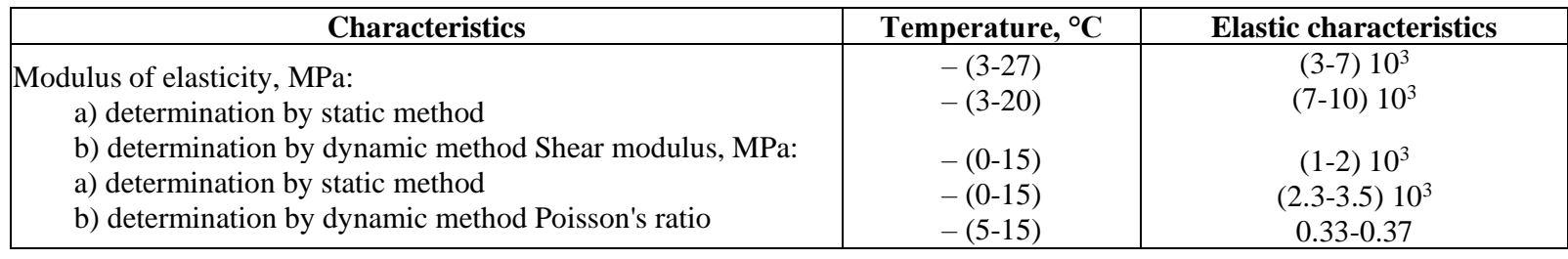

Table 2. Ice strength.

\begin{tabular}{|c|c|c|}
\hline Deformation type & Temperature, ${ }^{\circ} \mathbf{C}$ & Tensile strength range, $\mathbf{M P a}$ \\
\hline Compression & $-(6-11)$ & $2.5-6.0$ \\
\hline Tensile & $-(0-18)$ & $0.7-1.5$ \\
\hline Bending & $-(3-15)$ & $0.5-2.5$ \\
\hline Shear & $-(0-15)$ & $0.5-1.2$ \\
\hline
\end{tabular}

peat has a more porous structure and differs significantly from peat that forms in the south of our country. In such peat, plant residues decompose more weakly, preserving its fibrous structure, since they almost immediately fall into a zone with low oxygen content and, accordingly, low oxidative ability. Peat with high content of strong (poorly decomposed) fibers can be effectively used as a reinforcing element in various compositions. The lower is the degree of peat decomposition, the stronger are fibers, and the better is the quality of the resulting composition. Peat is the most promising reinforcing material for ice hardening, both in terms of its availability (local material), and low cost.

Studies to determine the complex of mechanical characteristics of ice with peat were carried out by G. Kagan during development of methodology for calculating the bearing capacity of a frozen peat cover at the base of fishing roads. These roads were the main transport network for development of oil fields in Western Siberia. During the tests, peat of high bogs was used with a minimum decomposition degree of plant residues. The degree of peat decomposition in the upper horizons of deposits was 5-10 percent. The studies were carried out in the laboratory of the Tyumen Industrial Institute $[1,9]$. When freezing, peat, like mineral soils, dramatically changes its properties. Frozen peat is a multicomponent system, the main elements of which are mineral particles, ice, plant fibers, water and gases. The gas content remains unchanged when freezing peat and is $4-5 \%$. When water is freezing it is transferred to its solid phase - ice and cementation of plant fibers by it provide a sufficiently high monolithicity and strength of frozen peat. The resulting structure makes it similar to artificial composite materials, in particular reinforced plastics. Thus, frozen peat is a natural composition in which ice serves as a binder and plant fibers as a reinforcing material. The work of such a material is determined by the properties of the constituent elements and their interactions.

Plant fibers in peat are oriented parallel to the freezing surface. The length of fibers varies in a wide range - from fractions of a millimeter to several centimeters, and the tensile strength varies from 16 to 86 $\mathrm{MPa}$. Another component of frozen peat - ice is a crystalline body. The existence of ice in nature is limited to a period of time with a negative temperature close to the melting point. The lowest temperature of natural ice differs from its melting point by only a few tens of degrees. Therefore, ice to a large extent exhibits rheological properties (creep, relaxation), and its resistance to external loads is determined by the time of their action. So, if the load action time is very short (instantaneous load) and plastic deformation does not have time to develop, ice deforms as an elastic body. In this case, ice destructs as a brittle material. The elastic characteristics of ice are given in table 1 [10].

The strength of ice is determined by the nature of ice formation, structure, temperature, mode and type of loading. The range of changes in the strength characteristics determined in the conditions of fast loading is shown in table 2 [10].

The development of creep deformation in ice is observed at almost any stress. It is known that if the stress of ice under load does not exceed a certain limit, then over time the creep rate is fixed and ice does not break. According to experimental data, the ultimate creep of ice at shear is $0.2 \mathrm{MPa}$ at a temperature of -1.8 ${ }^{\circ} \mathrm{C}$. Upon deformation in the steady-state creep stage, ice is considered as a viscous liquid.

Plant fibers have a higher modulus of elasticity than ice, so when they are used together, the tensile strength of frozen peat is greater than that of ice. Thus, the mechanical properties of the ice - peat composition and their resistance to loads are determined by the joint work of ice and plant fibers.

There are few experimental data on mechanical properties of frozen peat. The elastic properties of frozen peat are manifested only under dynamic loads. So, the elastic constants can be defined using dynamic test methods. Using this method, the elastic modulus was determined for the ice-plant fiber composition at a temperature of $-5^{\circ} \mathrm{C}$, and are presented in table 3 [7].

As it can be seen, with an increase in the content of wood fiber the elastic modulus decreases. Thus, the elastic modulus of a composition with a $7 \%$ content of wood fiber decreases by $25 \%$ as compared to the elastic modulus of pure ice. 
Table 3. The elastic modulus $E$ the ice-plant fiber composition.

\begin{tabular}{|c|c|}
\hline Content of wood fiber to the total sample mass, \% & Average value of $\boldsymbol{E}, \mathbf{M P a}$ \\
\hline 0 & 8700 \\
\hline 3 & 8300 \\
\hline 7 & 6500 \\
\hline
\end{tabular}

The results of these studies showed that the strength characteristics of frozen peat are similar to those with addition of wood fiber. The materials of these studies are given in [9].

Thus, ice with fiber content can be considered as a composite material, the filler of which is fibers, and ice serves as a binder. If wood fiber is used in this composition, it represents an artificial composition, and if plant fibers, it represent the natural one, that is, frozen peat.

\section{Results and Discussion}

As noted above, peat soil is widespread in areas adjacent to the Arctic zone and in the Far North, and it can be considered where as local material. The use of hardened ice in the Arctic opens up opportunities for the use of more heavy-duty energy-efficient engineering structures there.

The structural design of a floating ice pier proposed by the authors [11] is an example of such an energyefficient structure. It involves construction of a floating ice pier in the Arctic, with optimal cost and using mainly local building materials. The pier design enables its long operation period involving mooring, parking and handling of ships at different times of year.

The essence of the reported technical solution is as follows. During formation of an ice sheet with a thickness that ensures the pier construction, its bearing mass of ice with the wood or plant fibers additives is frozen, and in the central part cavities are formed to ensure circulation through them of air of negative temperatures.

Usually hardened ice is obtained using layer-by-layer distribution of fibers from various reinforcing materials on a previously prepared surface, followed by filling them with a layer of water and cooling to hardening.
The hardened ice can be produced using various devices, the general principle of which is a layer-bylayer deposition of pulp, a water mixture and a 3-6\% fibrous material on a frozen surface, followed by forced cooling to hardening. The number of pulp freezing cycles depends on the required thickness of the structure. Hardened ice does not contain air inclusions and areas with increased internal stress, which positively affects its strength [12].

The freezing of ice mass is carried out using formwork installed along its outer contour, which includes layers of heat- and waterproofing.

The cavity can be formed using formwork of pipes made of various materials - metal, composite, flexible shells, etc. The use of high-strength materials, such as metal, provides increased rigidity and increased structural strength of the floating pier.

The cavities in the pier body provide its necessary buoyancy and thermal stability of the frozen mass when air of negative temperatures circulates through them. In the winter period, cooling is carried out due to circulation of external air in the cavities. If necessary, in warm period, artificial cooling of air supplied to the cavity is used.

This allows one to freeze the pier mass with a height greater than the height of the natural frozen cover, but at the same time thawing from the bottom is excluded. Thus, these piers can be used as both temporary and permanent structures.

The figure shows a cross section of a floating flax pier. It is an artificially frozen mass of ice with addition of fibers 1 , inside of which cavities 2 are formed using pipes 3 as formwork and a device along the contour of the mass of protective layer 4, including formwork during freezing of the ice-fiber mass, heat and waterproofing.

The structure can be of any dimensions, which is

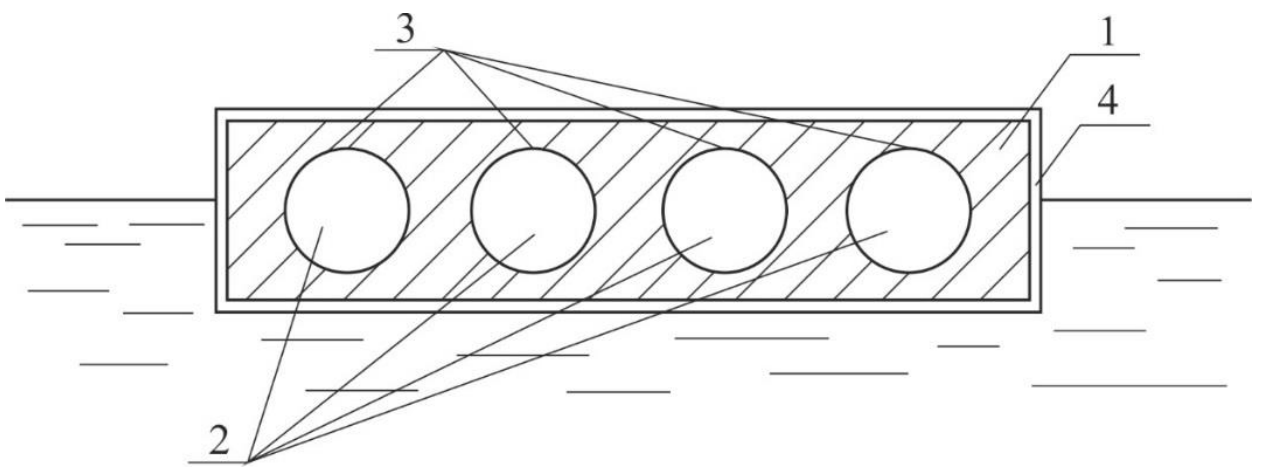

Fig. 1. Cross section of a floating ice pier: 1 - artificially frozen massif of ice with addition of fibers; 2 - cavities inside pipes; 3 pipes; 4 - formwork for freezing the ice-fiber array, heat- and waterproofing. 
selected according to the customer requirements. For comparison of cost indicators we considered dimensions similar to the three sequentially connected sections of the PM-61M metal floating pier connected with a 17-meter access bridge (length of $125 \mathrm{~m}$, side height of $2.2 \mathrm{~m}$, hull width of $8.2 \mathrm{~m}$ ), which was ordered by a shipyard in Murmansk in April 2020. The estimated cost of delivery, assembly, installation and unfastening of the analogue, PM-61M metal pier, is currently 130 million rubles. The cost of the proposed construction is 31.5 million rubles, comprising 16 million rubles for metal pipes of 1.6 diameters and inserts; 3.5 million rubles for in-line axial fans and equipment for cooling in the summer period, 0.5 million rubles for peat, 7 million rubles for formwork and insulation; 4.5 million rubles for installation and unfastening. The service life of such a structure is unlimited; periodic replacement or repair of fans and cooling systems is required in accordance with their service life.

\section{Conclusions}

In the difficult natural conditions of the Far North regions, the use of traditional piers, floating piers and pier facilities is expensive and ineffective due to remoteness from construction bases. The proposed platform - a pier made of hardened ice can be produced on site in a short time and from local materials, and it requires only several fans and a cooling unit in the summer. Therefore, this solution can be proposed for the quick and cost-effective development of the northern territories, and the technology of hardened ice will find its application in construction of modern ice structures, including piers, roads, runways and other facilities as a part of creation a new innovative infrastructure in the Russian Arctic region.

\section{References}

[1] G.L. Kagan, Strength characteristics of frozen peat and methodology for their study in relation to the calculation of roads on the frozen cover of swamps, thesis for the degree of candidate of geological and mineralogical sciences (Tyumen, 143, 1974).

[2] I.S. Peschansky, Glaciology and ice engineering (Leningrad: Gidrometeoizdat, 464, 1967).

[3] V.V. Lavrov, Deformation and strength of ice (Leningrad: Gidrometeoizdat, 208, 1969).

[4] V.G. Zanegin, N.G. Khrapatyi, Experimental studies of ice strength, Transactions of the Leningrad Polytechnic Institute 361, 85-87 (1978).

[5] N.A. Tsytovich, Mechanics of frozen soils (Moscow: Vyschaya Shkola, 448, 1973).

[6] R.L. Kobl, U.D. Kingeri, Artificial hardening, reinforcement of ice, in the book: Ice and snow, Properties, processes, use (Moscow: Mir, 480, 1966).

[7] N.F. Savko, N.M. Tupitsin, Yu.V. Yushkov, et al., Construction of roadbed on a frozen peat base, Automobile Roads 10, 4-5 (1972).
[8] G.L. Kagan, I.S. Peschansky, Z.I. Schweinstein, Yu.L. Nazintsev, Study of strength properties of a new ice-fiber material, Transactions of coordination meetings on hydraulic engineering, XXIII (Moscow: Publishing House Energiya, 1965).

[9] S.S. Vyalov, G.L. Kagan, A.N. Voevoda, V.I. Muravlenko, Construction of commercial structures on frozen peat (Moscow: Nedra, 144, 1980).

[10] K.F. Voitkovsky, Mechanical properties of ice (Moscow: Publishing house of USSR Academy of Sciences, 100, 1960).

[11] G.L. Kagan, A.Yu. Velsovskij, The method of construction an ice pier in the Arctic, Patent 2715034 of the Russian Federation, MPK7 E02B 17/00, B63B $35 / 44$, applicant and patent holder Vologda State University, 2019104118, declared 14.02.2019, publ. 21.02.2020, bull. no. 6, 5 .

[12] V.I. Moiseev, A.V. Panyushkin, N.K Vasil'ev, The method of formation of hardened ice, Certificate of authorship USSR, SU 1249277 A1, MPK F25C 1/12. applicant Leningrad Institute of Railway Engineers named after V.N. Obraztsov, 3911768, declared 07.01.1985, publ. 07.08.1986. 